\title{
CD54+ rabbit adipose-derived stem cells overexpressing HIF-1a facilitate vascularized fat flap regeneration
}

\author{
De-Quan Li ${ }^{1, *}$, Guan-Ming Lu' ${ }^{2, *}$, Yi-Dan Liang ${ }^{3, *}$, Zhi-Jie Liang ${ }^{4}$, Min-Hong Huang ${ }^{4}$, \\ Qi-Liu Peng ${ }^{3}$, Dong-Hua Zou ${ }^{5}$, Rong-He Gu${ }^{6}$, Fang-Tian Xu7 , Hui Gao7, Zhen-Dong \\ Chen ${ }^{7}$, Guang-Yi Chi ${ }^{8}$, Zhong-Heng $\mathrm{Wei}^{2}$, Li Chen ${ }^{9}$ and Hong-Mian $\mathrm{Li}^{8}$ \\ ${ }^{1}$ Department of Mammary Glands Surgery, The Third Hospital of Nanchang City, Nanchang 330009, China \\ ${ }^{2}$ Department of Glands Surgery, The Affiliated Hospital of Youjiang Medical University for Nationalities, Baise 533000, China \\ ${ }^{3}$ Central Laboratory of Medical Science, The Fifth Affiliated Hospital of Guangxi Medical University, Nanning 530022, China \\ ${ }^{4}$ Department of Mammary Glands Surgery, The Fifth Affiliated Hospital of Guangxi Medical University, Nanning 530022, China \\ ${ }^{5}$ Department of Neurology, The Fifth Affiliated Hospital of Guangxi Medical University, Nanning 530022, China \\ ${ }^{6}$ Department of Orthopedic Surgery, The Fifth Affiliated Hospital of Guangxi Medical University, Nanning 530022, China \\ ${ }^{7}$ Department of Orthopedics, The First Affiliated Hospital of Gannan Medical University, Ganzhou 341000, China \\ ${ }^{8}$ Department of Plastic and Aesthetic Surgery, The Fifth Affiliated Hospital of Guangxi Medical University, Nanning 530022, \\ China \\ ${ }^{9}$ Department of Neurology, The First Affiliated Hospital of Guangxi Medical University, Nanning 530021, China \\ *These authors contributed equally to this work
}

Correspondence to: Hong-Mian Li, email: 18022081568@163.com

Keywords: rabbit adipose-derived stem cells, HIF-1a, adipogenic differentiation, engineered fat flaps, angiogenesis

Received: January 31, 2017 Accepted: March 22, $2017 \quad$ Published: April 01, 2017

Copyright: Li et al. This is an open-access article distributed under the terms of the Creative Commons Attribution License 3.0 (CC BY 3.0 ), which permits unrestricted use, distribution, and reproduction in any medium, provided the original author and source are credited.

\section{ABSTRACT}

Fat flap transplantation is frequently performed in patients suffering from soft tissue defects resulting from disease or trauma. This study explored the feasibility of constructing vascularized fat flaps using rabbit adipose-derived stem cells (rASCs) and collagen scaffolds in a rabbit model. We evaluated rASCs proliferation, paracrine function, adipogenesis, vascularization, and CD54 expression, with or without HIF-1a transfection in vitro and in vivo. We observed that adipogenic differentiation potential was greater in rASCs with high CD54 expression (CD54+rASCs) than in those with low expression (CD54-rASCs), both in vitro and in vivo. HIF-1a overexpression not only augmented this effect, but also enhanced cell proliferation and paracrine function in vitro. We also demonstrated that HIF-1a-transfected CD54+rASCs showed enhanced paracrine function and adipogenic capacity, and that paracrine function increases expression of angiogenesis-related markers. Thus, CD54 ${ }^{+}$rASCs overexpressing HIF-1a enhanced large volume vascularized fat flap regeneration in rabbits, suggesting CD54 may be an ideal candidate marker for ASCs adipogenic differentiation.

\section{INTRODUCTION}

Soft tissue regeneration via adipose tissue engineering is a growing field addressing current clinical demands related to various soft tissue defects [1-4]. Soft tissue substitutes are often required following disease or tissue trauma, such as in adipose or muscle tissues. Soft tissue defects may affect patient physical appearance, cause emotional disturbances, and/or impair function. Currently, autologous tissue flaps, fat, or commercially available fillers are commonly used in reconstructive surgeries, specifically for repairing facial tissue defects and tumor resection sites. Although these strategies achieve clinical success, subsequent volume losses and secondary donor-site deformities challenge long-term efficacies. Emerging tissue engineering strategies represent 
innovative approaches for many clinical challenges. Such strategies include incorporating seed cells, biodegradable scaffolds, and microenvironments to provide specific inductive signals for tissue regeneration.

Adipose-derived stem cells (ASCs) represent a readily available supply of mesenchymal stem cells (MSCs) from lipo-aspirates [5-7]. ASCs exhibit enhanced proliferation and reduced senescence, and do not trigger immunological rejection [8]. ASCs may differentiate into chondrocytes, osteoblasts, adipocytes, myocytes, or neuronal-phenotype cells in vitro or in vivo [9-13]. Efforts directed toward promoting ASCs adipogenic differentiation have included growth factor or induction agent administration, other angiogenic methods, and the use of appropriate scaffolds [14-19]. ASCs exhibit poor adipogenic differentiation capacity under nonadipogenic-inducing conditions. We hypothesized that some cluster of differentiation (CD) markers could be closely related to adipogenic differentiation-related functions in ASCs. Our previous work showed that transfecting human breast adipose-derived stem cells (HBASCs) with $C X C R 4$ effectively improved survival of free fat transplants [20]. We also found that ginsenoside Rg1 and platelet-rich fibrin co-administration improved HBASCs function in soft tissue regeneration engineering [21]. In this study, we purified CD54+rASCs using immunomagnetic beads, transfected them with $H I F$ $1 \alpha$, and seeded them on three-dimensional, porous, collagen type I sponge scaffolds in vitro. Paracrine function was assessed prior to implantation. Finally, we assessed vascularized fat flaps constructed using $H I F-1 \alpha$ transfected $\mathrm{CD}^{2} 4^{+} \mathrm{rASCs}$ for optimizing adipose tissue regeneration in vivo.

\section{RESULTS}

\section{rASCs growth characterization, immunophenotype, and multipotency}

Homogeneous rASCs growing in a monolayer with a spindle-shaped morphology were observed by phasecontrast microscopy after primary culture for 7-10 d, reaching 80-90\% confluence (Figure 1). These rASCs proliferated rapidly. During subculture, P3 rASCs reached the same level of confluence within 3-4 d with a 1:3 split ratio (Figure 1). This demonstrated that rASCs resemble other ASCs in terms of morphology and proliferative capacity. rASCs expressed the mesenchymal surface markers CD29, CD44, CD54, CD73, CD90, CD105, and HLA-ABC, as determined by flow cytometry (Table 1). In contrast, $<7 \%$ of rASCs expressed the hematopoietic markers CD31, CD34, and CD45, and the histocompatibility antigen class II HLA-DR-DP-DQ. After DiI labeling, rASCs cytoplasms showed red fluorescence (Figure 1).

Subconfluent P3 rASCs were cultured with adipogenic, osteogenic, and chondrogenic induction media, and lineage-specific cell morphologies were observed following 2, 3, and 2 weeks of culture, respectively. Adipocytes, osteoblasts, and chondrocytes can be identified by positive oil red $\mathrm{O}$, alizarin red, or alcian blue staining, respectively. Lineage-specific histological staining was performed using these dyes, and results confirmed that rASCs differentiated into adipocytes, osteoblasts, and chondrocytes following culture in the relevant induction medium (Figure 1). These results validated $\mathrm{rASCs}$ multipotency

\section{Effect of HIF-1 $\alpha$ transfection on rASCs proliferation in vitro}

CCK-8 assays were performed on HIF-1 $\alpha$ transfected, blank virus-transfected, and control rASCs. Beginning $3 \mathrm{~d}$ after culture, HIF-1 $\alpha$-transfected cell proliferation rate was higher than that of the blank virustransfected and control cells, and HIF-1 $\alpha$-transfected cell doubling time was shorter than that of the blank virus -transfected and control cells $(P<0.001$, Figure 2$)$.

\section{Paracrine signal levels after rASCs HIF-1 $\alpha$ transfection}

Three and $7 \mathrm{~d}$ after HIF-1 $\alpha$ transfection, supernatant levels of hepatocyte growth factor (HGF), vascular endothelial growth factor (VEGF), endothelin-1 (ET-1), basic fibroblast growth factor (b-FGF), insulinlike growth factor-2 (IGF-2) and heat shock protein 70 (HSP70) were measured in the treatment and control groups by ELISA. After $3 \mathrm{~d}$, supernatant levels of HGF, VEGF, ET-1, b-FGF, IGF-2, and HSP70 were lower in the untransfected group than in the transfected group, with fold changes of 1.27 vs. $3.66,1.38$ vs. $3.15,1.04$ vs. 2.35 , 1.03 vs. $3.27,1.09$ vs. 2.42 , and 1.12 vs. 2.25 , respectively. After $7 \mathrm{~d}$, supernatant levels of HGF, VEGF, ET-1, b-FGF, IGF-2, and HSP70 were also lower in the untransfected group than in the transfected group, with fold changes of 1.89 vs. $5.13,1.45$ vs. $4.67,1.11$ vs. $3.67,1.08$ vs. 5.15 , 1.12 vs. 4.36 , and 1.17 vs. 4.38 , respectively (Figure 3 ).

\section{Effect of HIF-1 $\alpha$ on rASCs adipogenic differentiation in vitro}

The four rASCs groups exhibited different adipogenic potentials in vitro. CD54 ${ }^{+}$ASCs contained more large oil red O-positive lipid droplets in their cytoplasm, and HIF-1 $\alpha$ transfection augmented this effect. However, CD54rASCs transfected with HIF-1 $\alpha$ (group C) and untransfected CD54rASCs contained fewer oil red O-positive lipid droplets (Figure 4). There were differences between groups $\mathrm{A}$ and $\mathrm{B}$, groups $\mathrm{A}$ and $\mathrm{C}$, groups $\mathrm{A}$ and $\mathrm{D}$, groups $\mathrm{B}$ and $\mathrm{C}$, groups $\mathrm{B}$ and $\mathrm{D}$, and groups $\mathrm{C}$ and $\mathrm{D}$ in adipocyte density and lipid concentration (Figure 4). 


\begin{tabular}{lc}
\hline Surface Markers & rASCs at P3 (mean \pm SD, $\%)$ \\
\hline CD29 & $97.3 \pm 1.2$ \\
CD44 & $98.1 \pm 0.7$ \\
CD54 & $92.4 \pm 1.1$ \\
CD73 & $95.2 \pm 0.8$ \\
CD90 & $99.2 \pm 0.5$ \\
CD105 & $99.4 \pm 0.3$ \\
HLA-ABC & $98.9 \pm 0.9$ \\
CD31 & $6.1 \pm 0.7$ \\
CD34 & $4.8 \pm 0.6$ \\
CD45 & $4.3 \pm 0.9$ \\
HLA-DP, DQ, DR & $3.9 \pm 0.5$ \\
\hline
\end{tabular}

$n=6$.
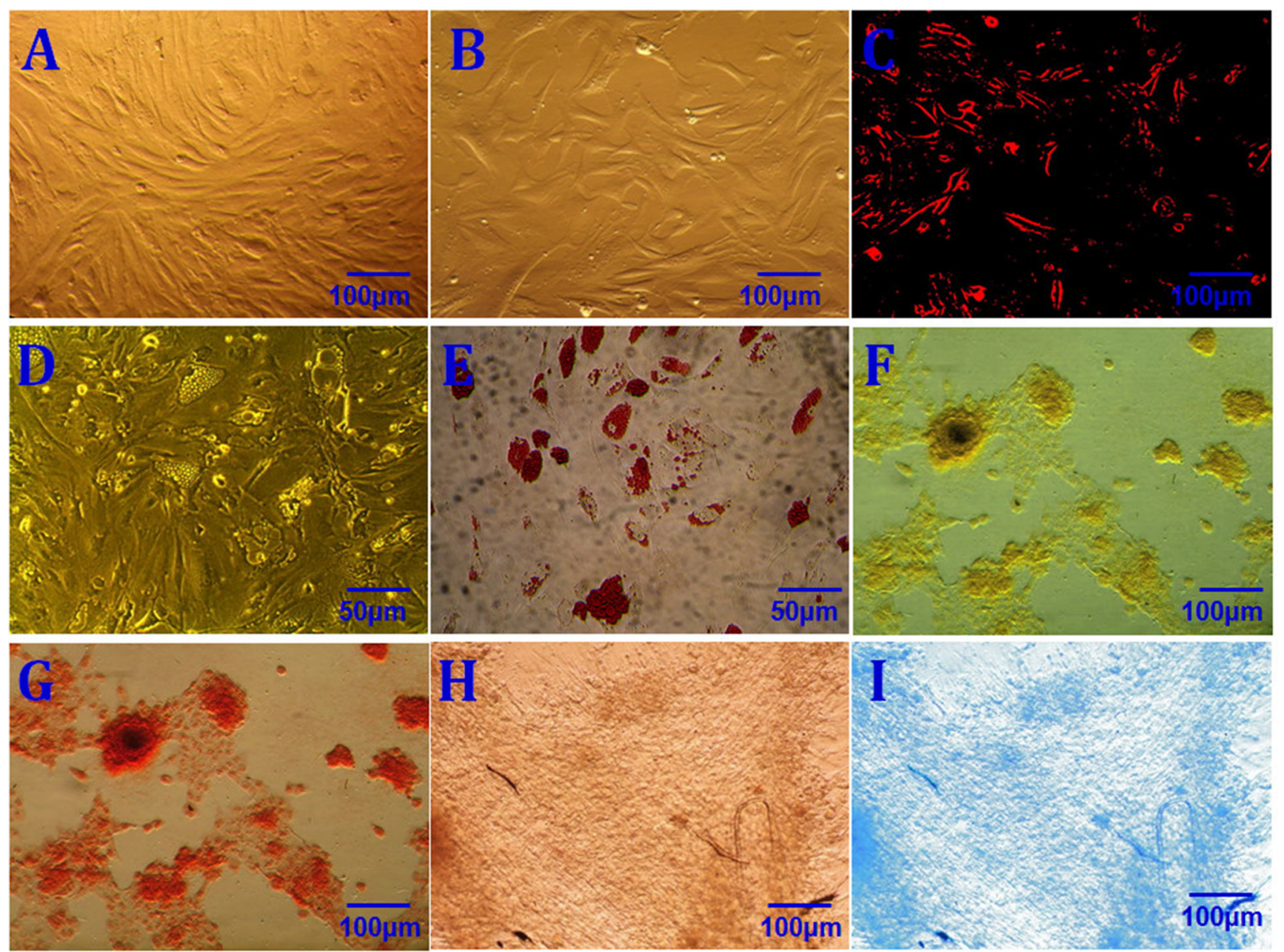

Figure 1: rASCs characterization. Morphological characterization of primary rASCs (A) Morphological characterization of P3 rASCs (B) DiI labeling of rASCs (DiI+) (C) Adipogenic induction conducted for 2 weeks before staining (D) Positive oil red O staining following 2 weeks of adipogenic induction (E) Osteogenic induction conducted for 3 weeks before staining (F) Positive alizarin red staining following 3 weeks of osteogenic induction (G) Chondrogenic induction conducted for 3 weeks before staining (H) Positive alcian blue staining following 2 weeks of chondrogenic induction (I) Scale bars: $50 \mu \mathrm{m}$ (D, E); $100 \mu \mathrm{m}$ (A-C, F-I). 


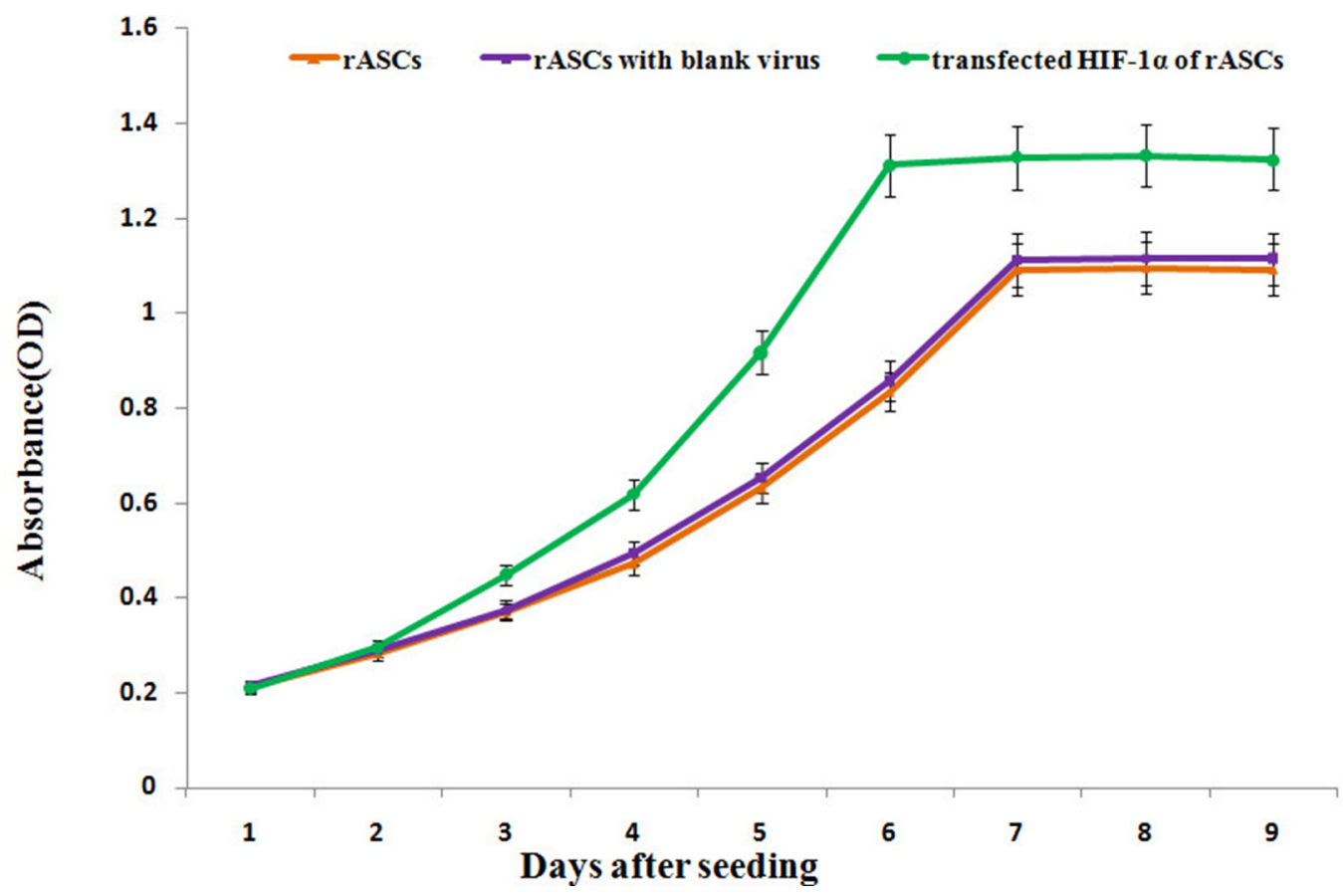

Figure 2: rASCs proliferation as assessed by a CCK-8 assay. HIF-1 $\alpha$-transfected rASCs displayed higher absorbance values than blank-transfected and control rASCs at every time point starting from d $3 . n=6, P<0.01$ (ANOVA).
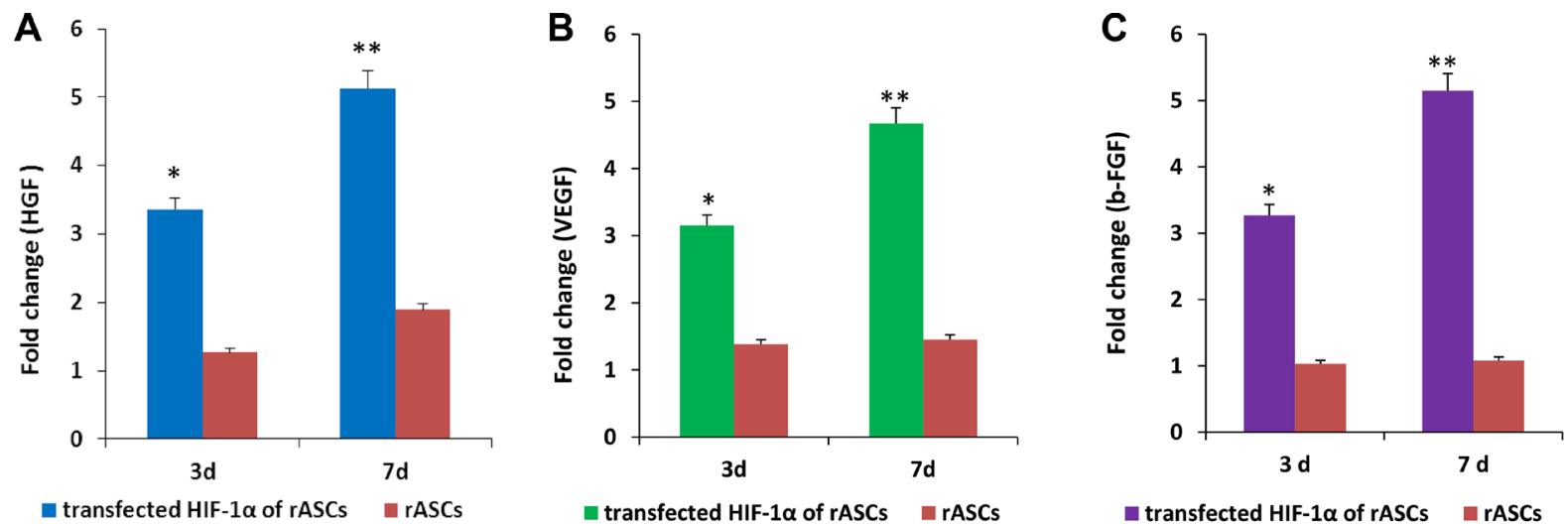

D

$\mathbf{E}$
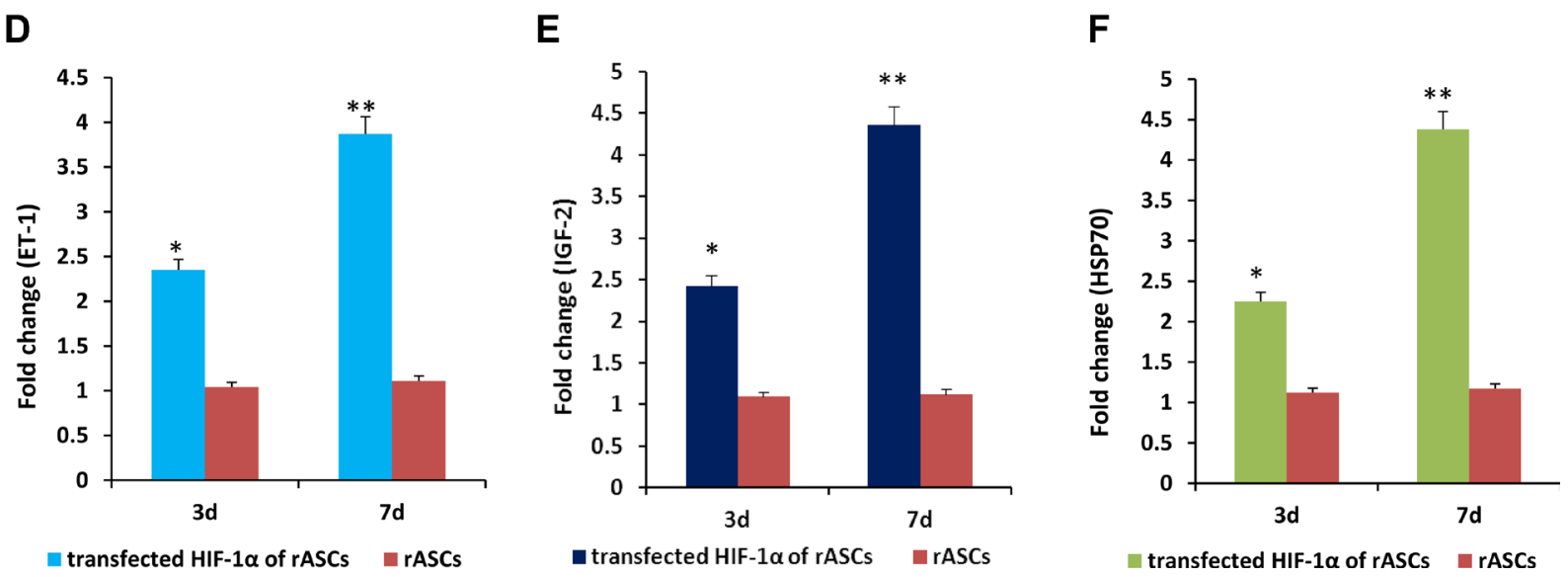

Figure 3: rASCs expression of paracrine factors after HIF-1 $\alpha$ transfection in vitro. Higher HGF (A), VEGF (B), b-FGF (C), ET-1 (D), IGF-2 (E), and HSP70 (F) expression were measured in the treated group than in the control group at 3 and 7 d. $n=3, P<0.01$ $(t$-test). 


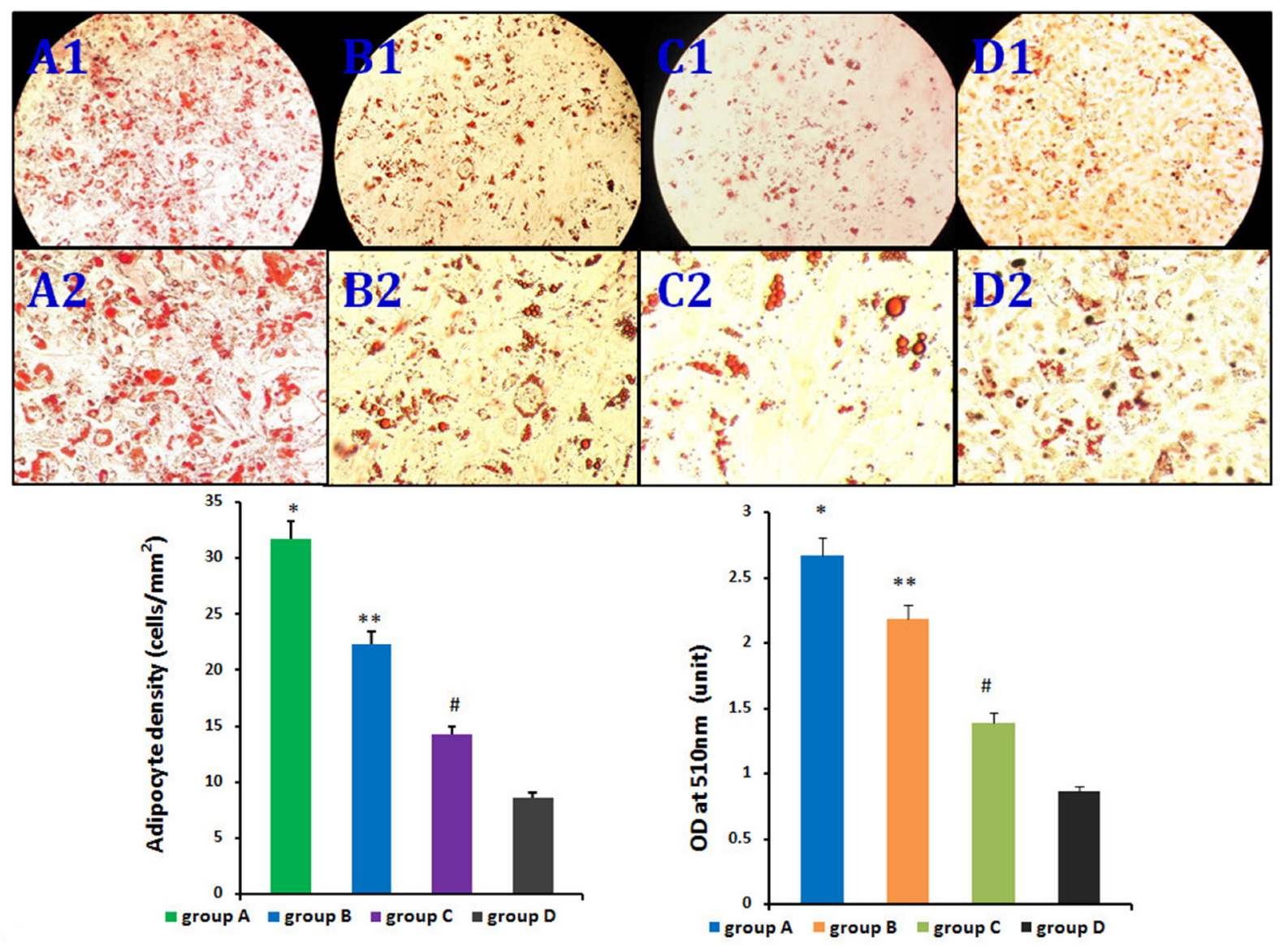

Figure 4: Influence of HIF-1 $\alpha$ on rASCs adipogenic differentiation in vitro. There were differences between group A and B, group $\mathrm{A}$ and $\mathrm{C}$, group $\mathrm{A}$ and $\mathrm{D}$, groups $\mathrm{B}$ and $\mathrm{C}$, groups $\mathrm{B}$ and $\mathrm{D}$, and groups $\mathrm{C}$ and $\mathrm{D}$ in adipocyte density and lipid concentration. ${ }^{*} P<$ $0.01,{ }^{*} P<0.01,{ }^{*} P<0.01$.
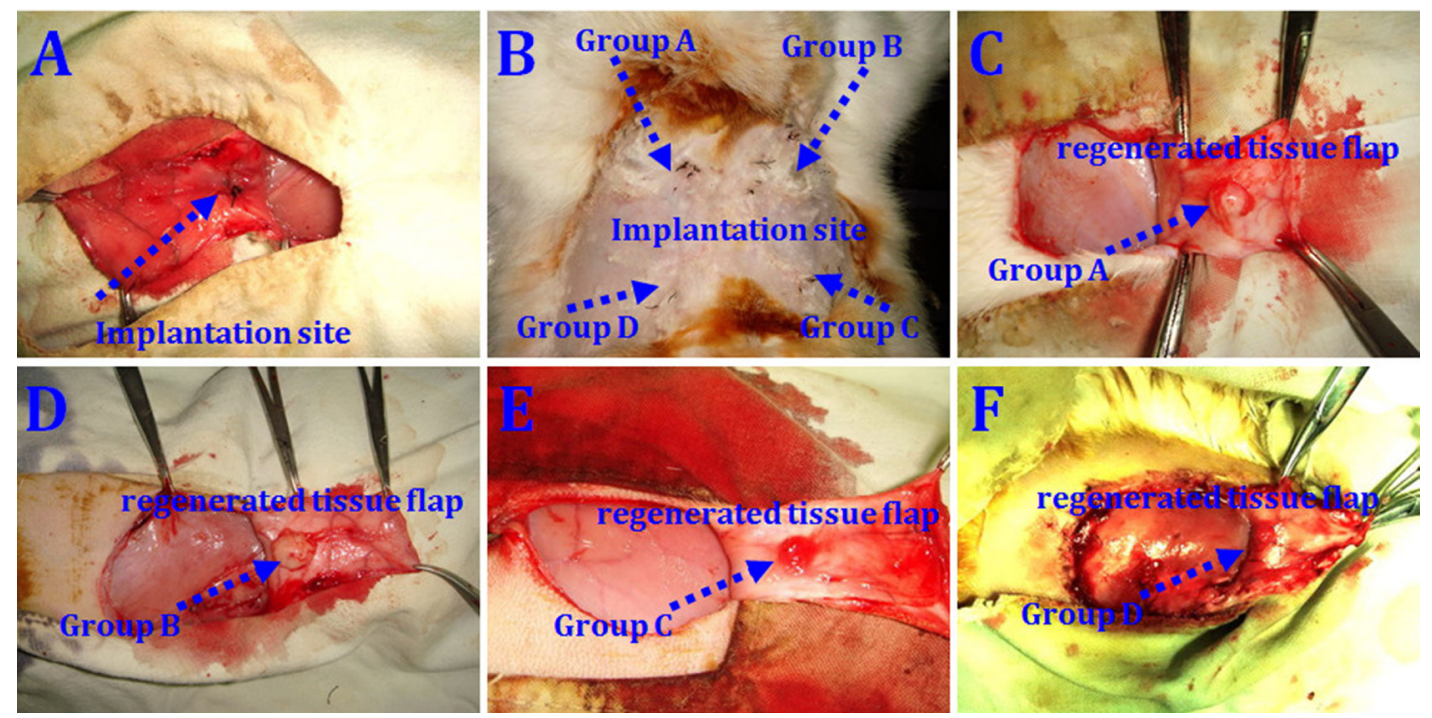

Figure 5: rASCs-loaded scaffold implantation in vivo. Cell-loaded scaffolds implanted immediately after the operation (A) At 12 weeks post-implantation, collagen scaffolds loaded with HIF- $1 \alpha$-transfected CD54 ${ }^{+}$rASCs (group A), CD54 ${ }^{+}$ASCs (group B), HIF-1 $\alpha-$ transfected CD54rASCs (group C), and CD54rASCs (group D) (B) Macroscopic findings of neogenetic tissue in groups A (C), B (D), C (E), and D (F). 
Table 2: Wet weights in each group $(\mathrm{mg}, n=20)$

\begin{tabular}{ccccc}
\hline group & A & B & C & D \\
\hline Wet weight & ${ }^{*} 532.6 \pm 61.4$ & ${ }^{* *} 417.8 \pm 52.5$ & ${ }^{*} 226.3 \pm 43.7$ & $163.5 \pm 38.9$ \\
\hline$* P<0.01,{ }^{* *} P<0.01,{ }^{\sharp} P<0.01$. & & &
\end{tabular}

\section{Neogenetic fat flaps macroscopic findings and histopathological assessment}

No animals died during the 12 weeks following implantation. Macroscopic findings indicated that regenerated tissue flaps had formed, and these were excised carefully for testing (Figure 5). Neogenetic fat flap wet weights were measured using an electronic balance (Table 2). Differences were found between groups A and B, groups $\mathrm{A}$ and $\mathrm{C}$, groups $\mathrm{A}$ and $\mathrm{D}$, groups $\mathrm{B}$ and $\mathrm{C}$, groups $\mathrm{B}$ and $\mathrm{D}$, and groups $\mathrm{C}$ and $\mathrm{D}$ (Figure 6). H\&E staining results showed that regenerated tissue flaps in all groups were composed of mature adipose tissue. Compared with the other three groups, group A contained the most mature adipose tissue and showed no signs of fibrosis. Group B also consisted predominantly of mature adipose tissue and showed less fibrosis than groups C or D. Groups C and D partially consisted of mature adipose tissue and showed more fibrosis than groups A and B. Moreover, the collagen sponges were observed to have degraded over the course of 12 weeks after implantation in vivo (Figure 7).

\section{Microvessel density (MVD) of regenerated fat flaps}

We histologically evaluated 10 fields/section from the centers of regenerated fat tissues to assess MVD. MVD was much higher in groups A than that of in the other three groups. In contrast, few microvessels were observed in group D. However, HIF-1 $\alpha$-transfected CD54-rASCs (group C) promoted neovascularization more so than untransfected CD54rASCs (group D) or untransfected CD54 ${ }^{+}$ASCs (group B). Thus, HIF-1 $\alpha$ transfection enhanced revascularization. (Figures 7-8).

\section{Oil red $O$ staining and quantitative measurement of adipogenesis}

Red-fluorescent cells were observed in regenerated fat flaps by fluorescence microscopy, indicating that these mature adipocytes had differentiated from DiIlabeled rASCs (Figure 7A4-7D4). Adipogenesis and lipid vacuole formation in neogenetic mature adipose tissue
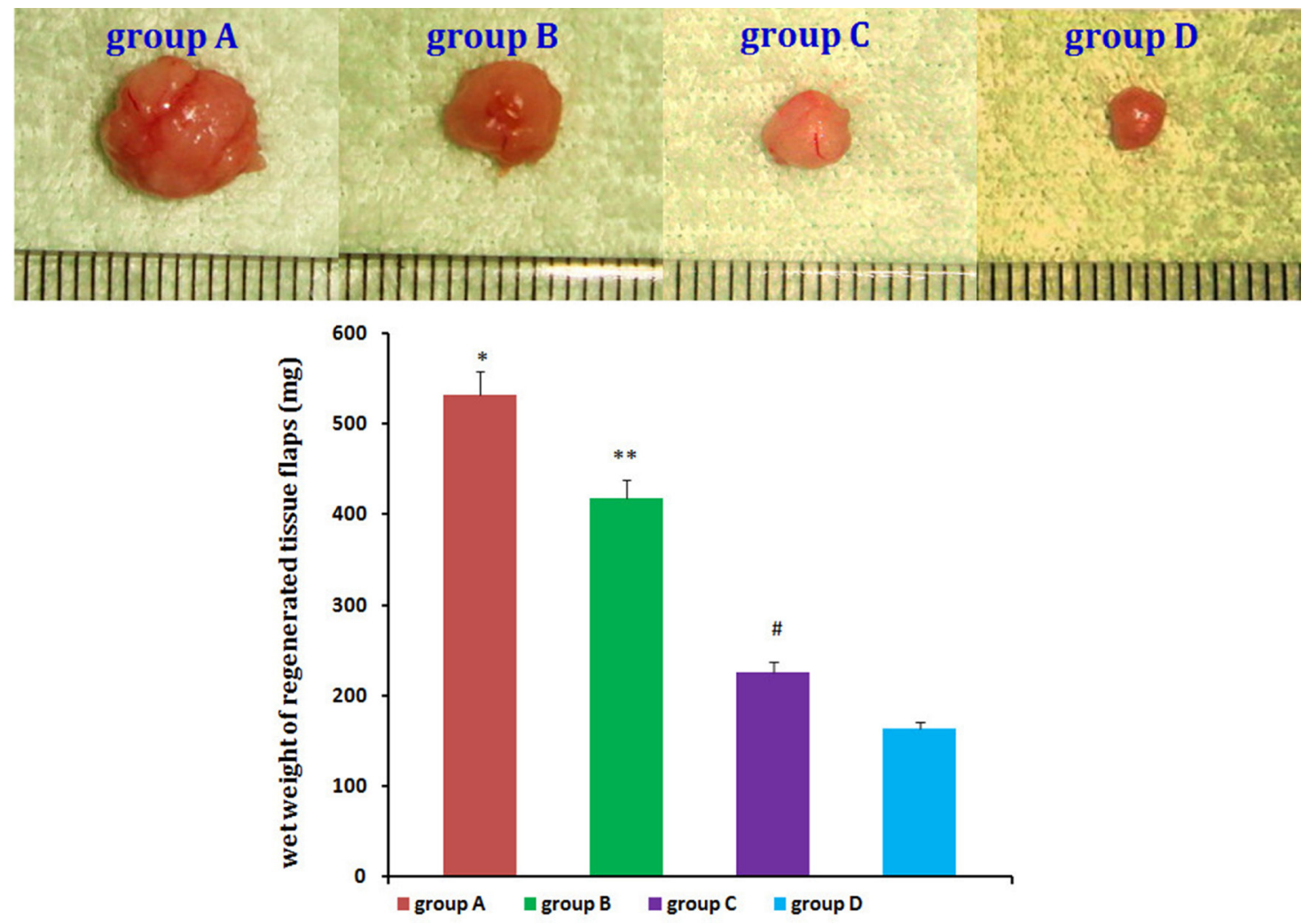

Figure 6: Neogenetic fat flap macroscopic findings. Wet weights of the neogenetic fat flaps in the four groups were measured and compared. $n=20,{ }^{*} P<0.01,{ }^{* *} P<0.01,{ }^{\sharp} P<0.01$ (ANOVA). 
sections were assessed by oil red O staining. CD54 ${ }^{+} \mathrm{rASCs}$ (group B) contained more large oil red O-positive lipid droplets in their cytoplasm, and transfection with HIF-1 $\alpha$ (group A) augmented this effect. CD54rASCs transfected with HIF-1 $\alpha$ (group C) and CD54rASCs contained fewer oil red O-positive lipid droplets (Figure 7). There were differences between groups $\mathrm{A}$ and $\mathrm{B}$, groups $\mathrm{A}$ and $\mathrm{C}$, groups $\mathrm{A}$ and $\mathrm{D}$, groups $\mathrm{B}$ and $\mathrm{C}$, groups $\mathrm{B}$ and $\mathrm{D}$, and groups $\mathrm{C}$ and $\mathrm{D}$ in adipocyte density and lipid concentration (Figure 8).

\section{Paracrine-related genes and proteins expression in neogenitic fat flaps}

Relative levels of HIF-1 $\alpha$, VEGF, b-FGF, ET-1, IGF-2, HSP70 were detected by real-time qPCR and western blot. Levels were higher in neogenetic fat flaps of groups A (HIF-1 $\alpha$-transfected CD54 ${ }^{+}$rASCs) and C (HIF$1 \alpha$-transfected CD54-rASCs) than in the other two groups (untransfected rASCs). (Figures 9-10).

\section{Adipogenesis-related genes and proteins expression in neogenitic fat flaps}

Relative levels of PPAR $\gamma, \mathrm{C} / \mathrm{EBP} \alpha$, and ADD1 were detected by real-time qPCR and western blot. PPAR $\gamma$ expression was lower in neogenetic fat flaps of groups A (HIF-1 $\alpha$-transfected CD54 $4^{+}$ASCs) and C (HIF- $1 \alpha-$ transfected CD54-rASCs) than in the other two groups (untransfected rASCs). However, $\mathrm{C} / \mathrm{EBP} \alpha$ and $\mathrm{ADD} 1$ levels were increased in groups $\mathrm{A}$ and $\mathrm{B}$ compared with groups $\mathrm{C}$ and D (Figures 11-12).

\section{DISCUSSION}

Surgical reconstruction procedures using autologous fat flaps are effective treatment approaches for various soft tissue defects caused by congenital deformities, traumatic injuries, or tumor resection [22-24]. However, limitations in clinical practice include poor retention of autologous fat and the occurrence of secondary donor-site deformities.

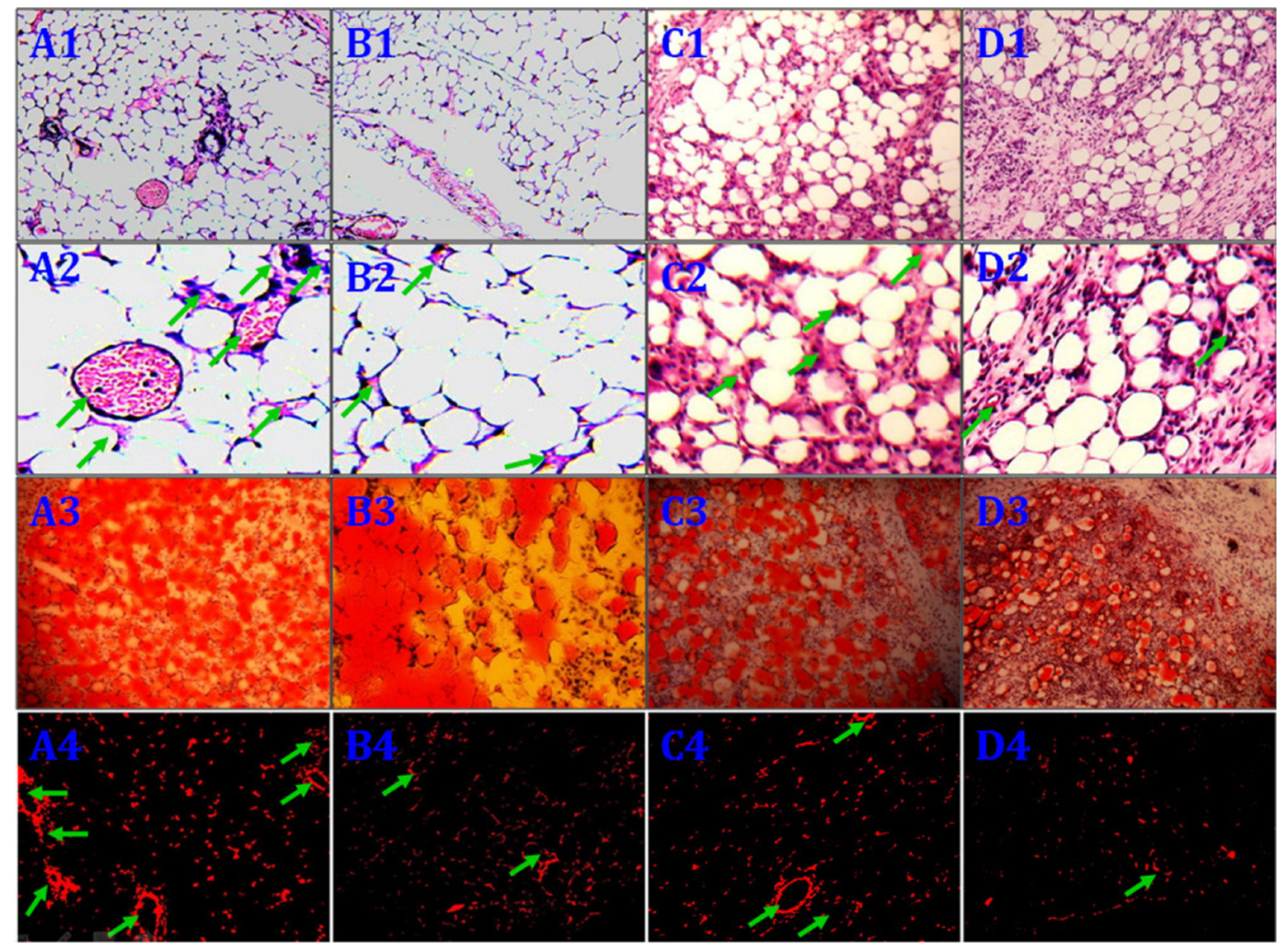

Figure 7: Histological evaluation of the neogenetic fat flaps after 12 weeks. Group (A) flaps consisted predominantly of mature adipose tissue and showed less fibrosis than flaps in the other groups A1.-2. Group (B) flaps also consisted predominantly of mature adipose tissue and showed less fibrosis than group (C and D) flaps B1.-2. Group C C1.-2. and D D1.-2. flaps consisted partially of mature adipose tissue and showed more fibrosis than flaps in the other two groups. In contrast to cells in groups C and D, CD54 ${ }^{+}$ASCs in group B contained more large oil red O-positive lipid droplets in their cytoplasm, and HIF-1 $\alpha$ transfection (group A) augmented this effect A3.-D3. DiI ${ }^{+}$cells were detected in neogenetic mature adipose tissue, indicating that these mature adipocytes differentiated from DiI-labeled rASCs A4.-D4. MVD: arrow. (A1.-D1., A3.-D3., A4.-D4. ×100, A2.-D2. ×400). 

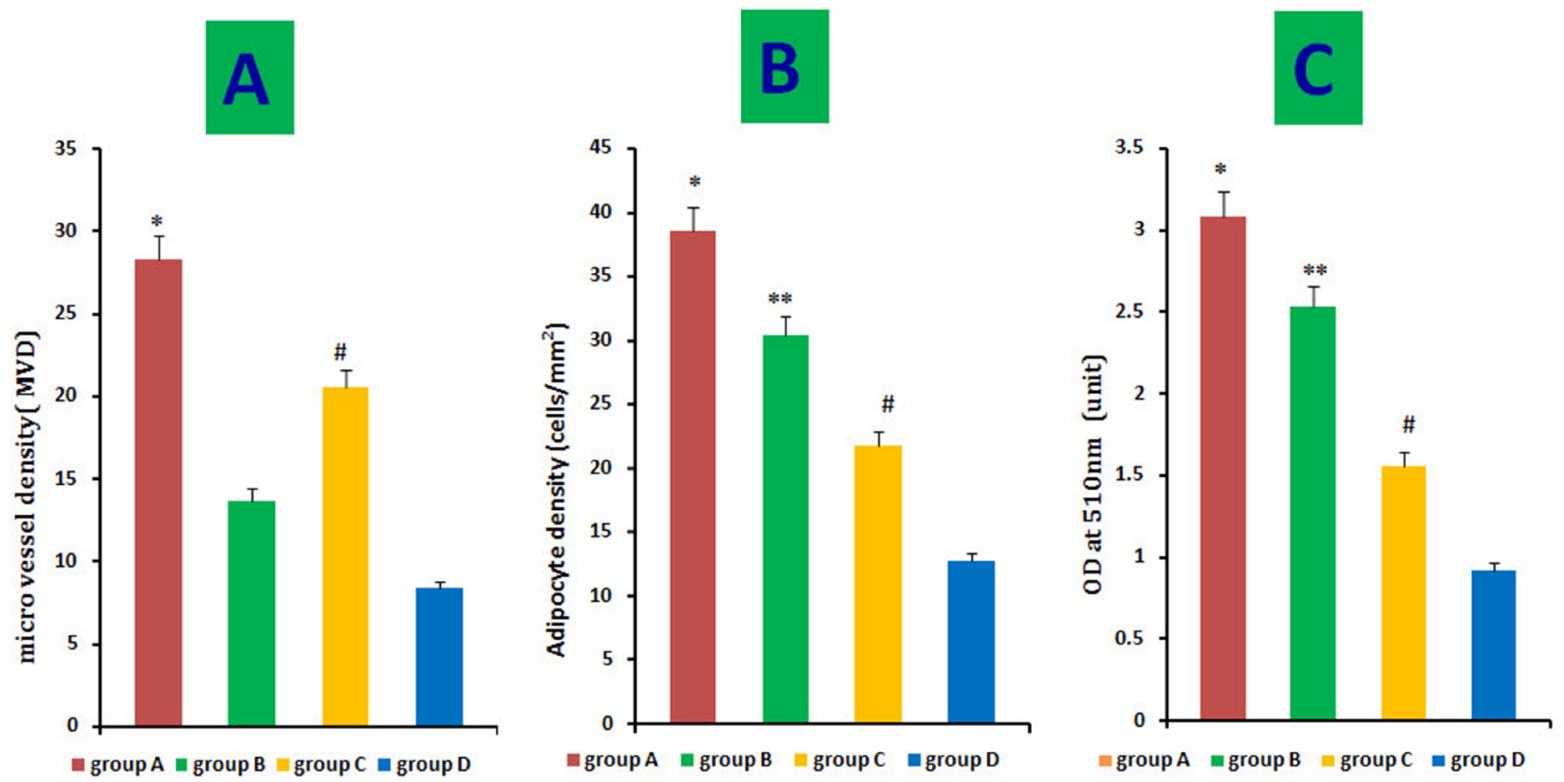

Figure 8: Quantitative measurement of adipogenesis and angiogenesis. Adipocyte density and intracellular lipid content were higher in groups (B) and (C) than in the control group, and HIF-1 $\alpha$ transfection $(\mathbf{A})$ augmented this effect (B-C). Histological evaluation of 10 fields/section taken from the center of the mature adipose tissue showed that the MVD was much higher in group A than in the other three groups, and MVD in group $\mathrm{C}$ was much higher than that in group $\mathrm{B}$ and $\mathrm{A}$, as determined by the $t$-test $\mathrm{C}$. ${ }^{*} P<0.01,{ }^{* *} P<0.01,{ }^{\#} P<0.01$.
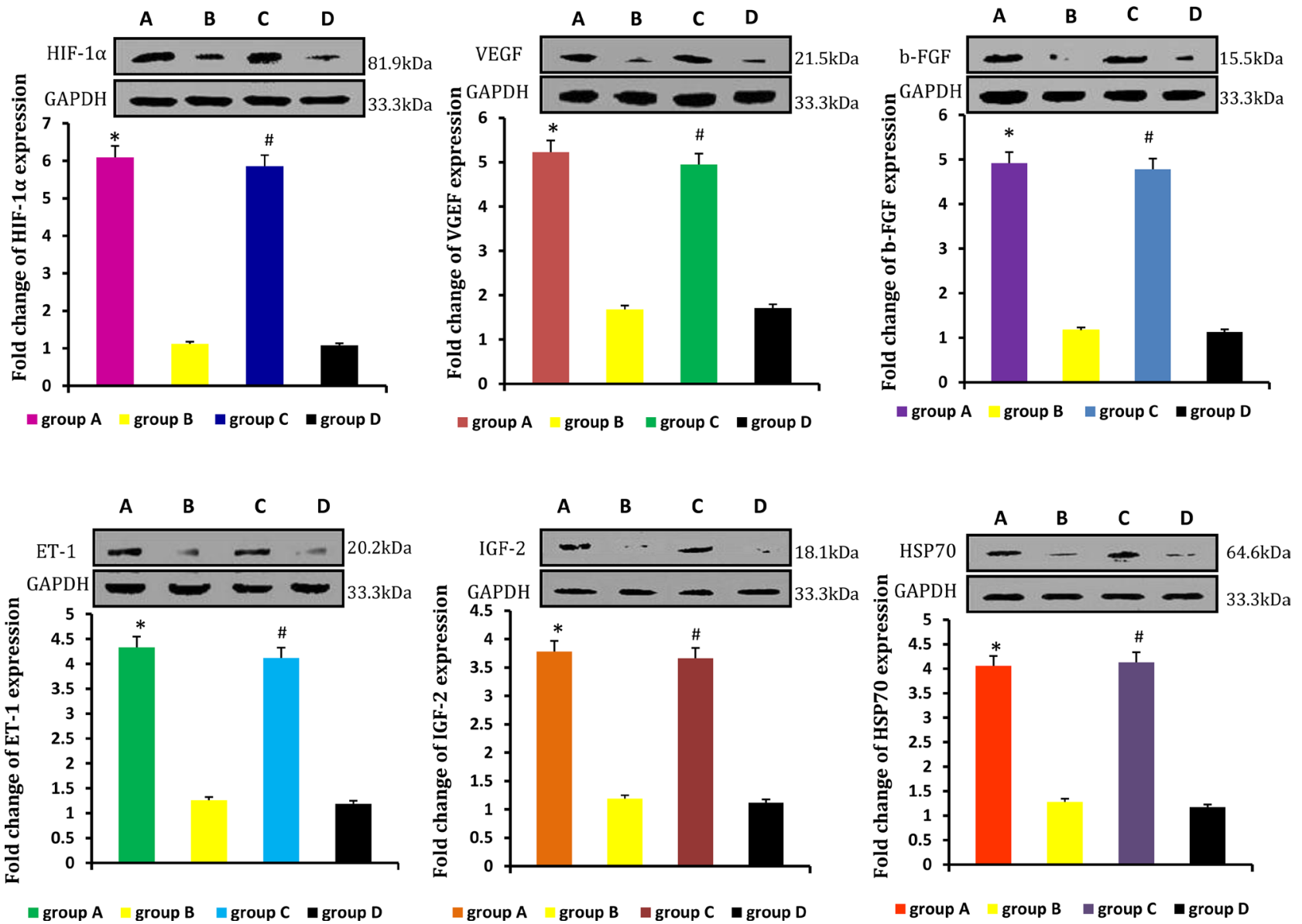

Figure 9: HIF-1 $\alpha$, VEGF, b-FGF, ET-1, IGF-2, and HSP70 mRNA levels were higher in the neogenetic fat flaps of groups $\mathbf{A}$ and $\mathbf{C}$ than in those of the other two groups. ${ }^{*} P<0.01,{ }^{*} P<0.01$. 
Engineering vascularized soft tissue flap grafts may provide clinical alternatives to autologous flap tissues.

HIF is a transcription factor induced under hypoxic conditions. HIF- $1 \alpha$ migrates into the nucleus to form a stable heterodimer with HIF-1 $\beta$ or binds to histone acetylation enzymes to avoid degradation [25]. HIF-1 $\alpha$ induces VEGF, platelet-derived growth factor (PDGF), and b-FGF expression, thereby enhancing angiogenesis and improving oxygenation of the environment [26-31]. However, the effects of HIF-1 $\alpha$ in ASCs remained unclear. Some studies showed that HIF-1 $\alpha$ is involved in cell proliferation during hypoxia [32-34].

This study assessed the adipogenic capacity of rASCs based on the CD54 marker, and found that rASCs with high CD54 expression exhibited stronger adipogenic differentiation potential in vitro. We examined rASCs proliferation and paracrine function with or without HIF- $1 \alpha$ transfection in vitro and in vivo, and found that HGF, VEGF, ET-1, b-FGF, IGF-2, and HSP70 were upregulated in transfected rASCs. These results showed for the first time that rASCs modified by HIF$1 \alpha$ exhibit enhanced proliferation and paracrine function.
Furthermore, macroscopic and histopathological findings suggested that $\mathrm{CD} 54^{+} \mathrm{rASC}$ exhibited greater adipogenic differentiation potential in vivo than CD54rASCs, and transfecting CD54 ${ }^{+}$ASCs with HIF-1 $\alpha$ augmented this effect. HIF-1 $\alpha$ gene modification or hypoxia preconditioning accelerated rASCs angiogenic potential, which was consistent with previous reports [33, 35].

PPAR $\gamma, \mathrm{C} / \mathrm{EBP} \alpha, \mathrm{ADD} 1$, and growth factors/ cytokines are closely involved in adipogenic differentiation [19, 36-37]. PPAR $\gamma$ and C/EBP $\alpha$ are transcription factors in different signaling pathways, and ADD1 expression can be used to represent degree of adipogenic differentiation [38-39]. In our study, C/EBP $\alpha$ and ADD1 levels were increased, and PPAR $\gamma$ levels were decreased in HIF- $1 \alpha-$ transfected CD54 $4^{+}$ASCs.

The transcription factor nuclear receptor PPAR $\gamma$ is an essential and sufficient factor for inducing adipocyte differentiation, and serves as a key marker of the adipogenic switch. However, in our work, PPAR $\gamma$ expression was decreased with rASCs adipogenic differentiation, which was promoted by HIF-1 $\alpha$ transfection. Other work showed that hypoxic conditions
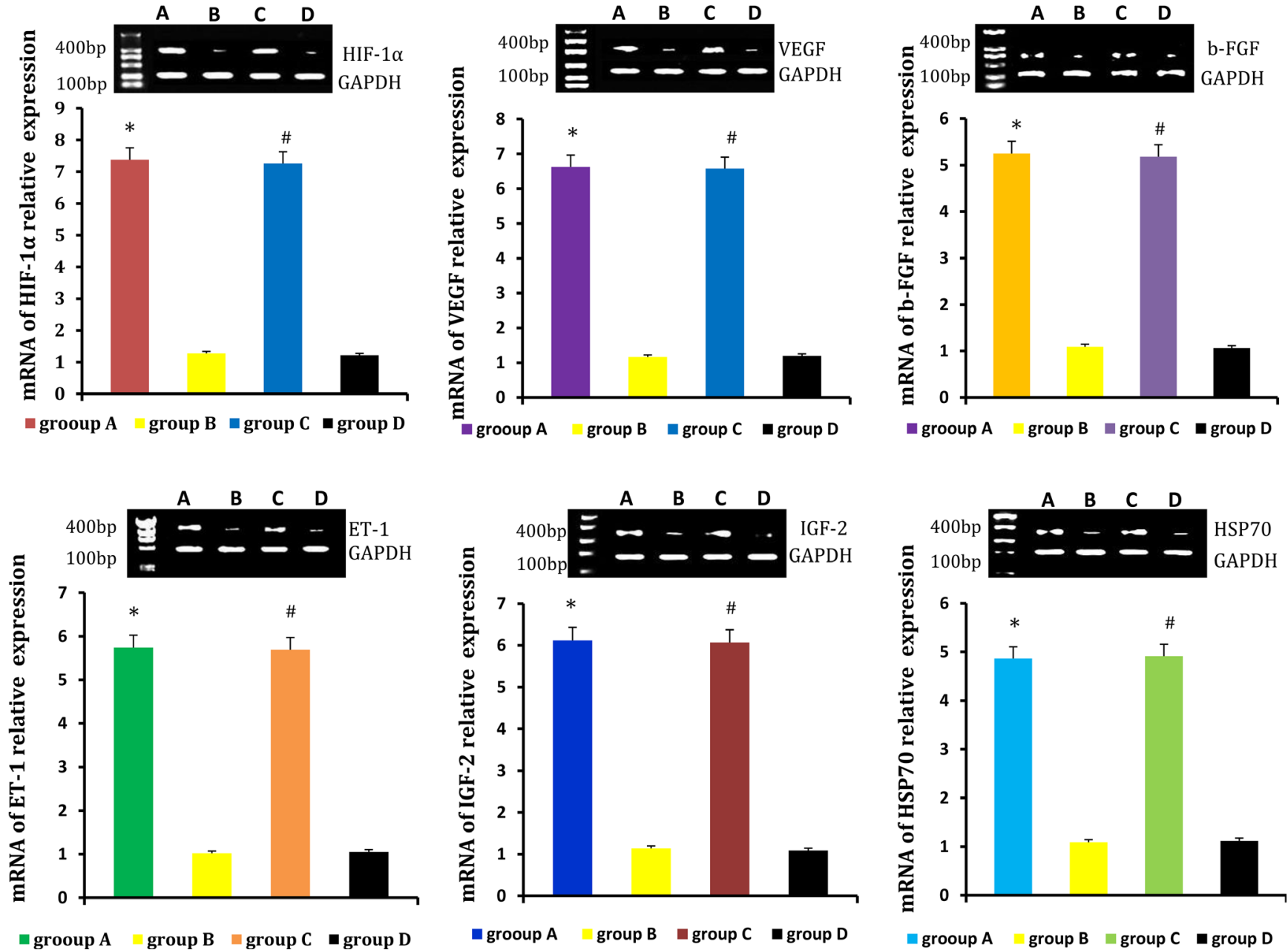

Figure 10: HIF-1 $\alpha$, VEGF, b-FGF, ET-1, IGF-2 and HSP70 protein levels were higher in the neogenetic fat flaps of groups $\mathbf{A}$ and $\mathbf{C}$ than in those of the other two groups. ${ }^{*} P<0.01,{ }^{\sharp} P<0.01$. 
enhanced the adipogenic potential of MSCs and that HIF$1 \alpha$ overexpression induced lipid droplet accumulation, while PPAR $\gamma$ inhibition upregulated adipocyte-specific gene expression [40]. These results demonstrated that HIF$1 \alpha$-induced adipogenic differentiation is independent of the PPAR $\gamma$-regulated pathway. Thus, HIF-1 $\alpha$ may induce rASCs adipogenic differentiation through a $\mathrm{C} / \mathrm{EBP} \alpha-$ dependent pathway. Based on our results, the PPAR $\gamma$ pathway may not be uniquely necessary for adipogenic differentiation.

ASCs directly form new vascular networks by differentiating into endothelial cells [41], and paracrine functions are also involved, e.g., in the secretion of angiogenic factors, such as VEGF, ET-1, b-FGF, and PDGF [42-43]. Our results showed that paracrine function and MVD were both increased in fat flaps containing modified rASCs. Angiogenesis is not the only process affected by paracrine signals; previous studies demonstrated that paracrine signals from MSCs promote cell proliferation, migration, and secretion independently of promoting angiogenesis [44]. Moreover, growth factors are necessary for efficient differentiation of ASCs into adipocytes [36]. Since HIF-1 $\alpha$-transfected rASCs not only exhibited enhanced proliferation and paracrine function, but also facilitated vascularized fat flap regeneration, HIF-1 $\alpha$ may promote early transplant neovascularization and enhanced rASCs adipogenic differentiation (Figure 13).

\section{MATERIALS AND METHODS}

\section{rASCs isolation, expansion, and identification}

Twenty subcutaneous adipose tissue samples were obtained from the groin fat pad of adult rabbits under anesthesia. Fibrous tissue was excised from fat pads and minced well with scissors at room temperature (RT). Experimental methods describing rASCs expansion, culture, and identification were described previously [45-46].

\section{DiI labeling, flow cytometric analysis, and immunoselection of rASCs}

Passage-3 (P3) rASCs were collected and labeled with 1,1'-dioctadecyl-3,3,3',3'-tetramethylin docarbocyanine perchlorate (DiI) for $24 \mathrm{~h}$. HIF-1 $\alpha$ was recombined with the target fragment, and the recombinant gene was introduced into a pAdEasy-1 adenoviral vector system. The virus was packaged, and titer was assessed. rASCs red autofluorescence was analyzed by inverted fluorescence microscopy and imaging (Leica,
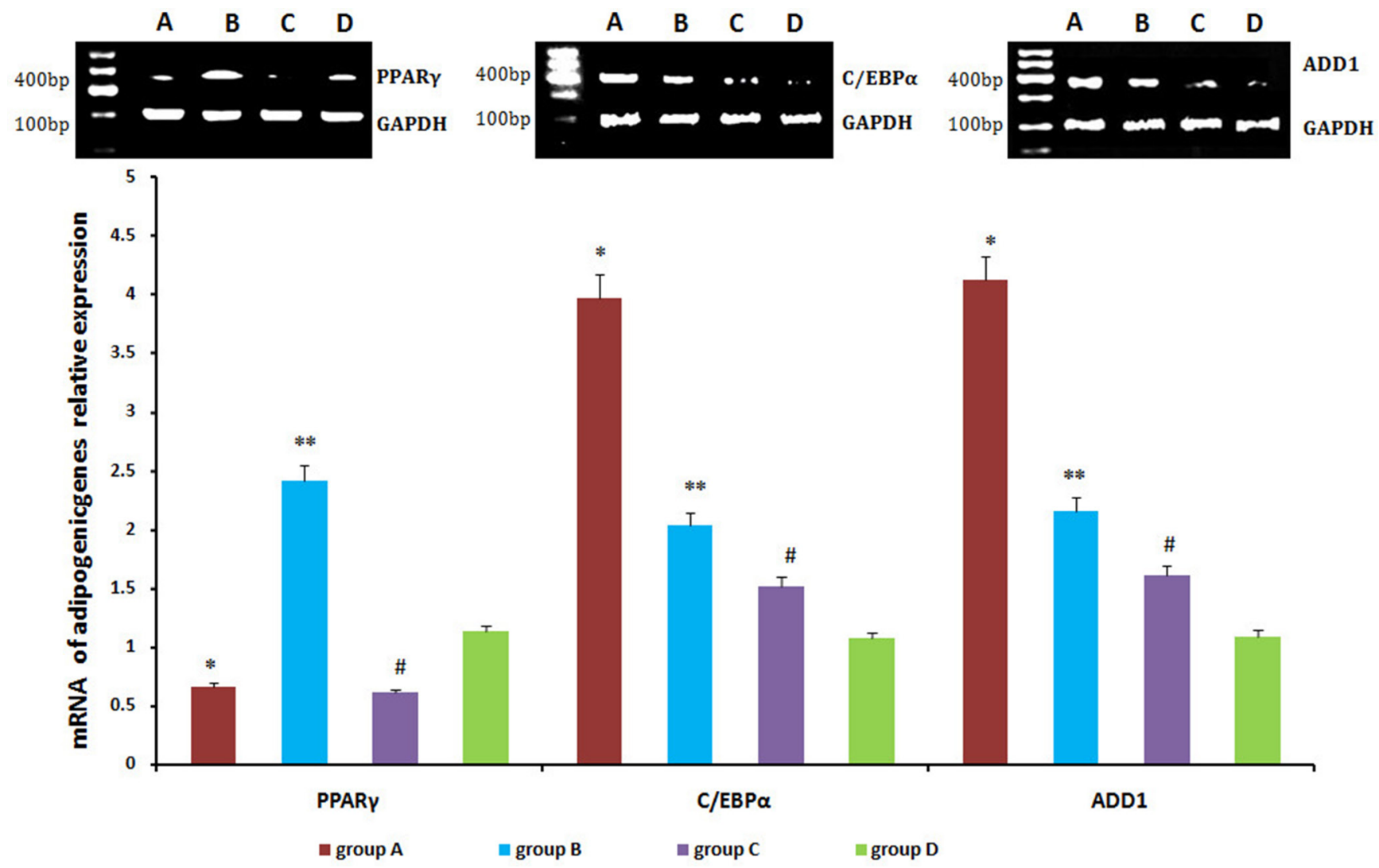

Figure 11: C/EBPa and ADD1 mRNA levels were higher in neogenetic fat flaps of group $A$ than in the other three groups. PPAR $\gamma$ was downregulated in the neogenetic fat flaps of groups $\mathrm{A}$ and $\mathrm{C}$ compared with the other two groups. $* P<0.01$, ${ }^{*} P<0.01,{ }^{\sharp} P<0.01$. 
Germany). Flow cytometry was performed using P3 rASCs. Cells were trypsinized using Accutase (Innovative Cell Technologies, San Diego, CA, USA), centrifuged at $1500 \mathrm{rpm}$ for $10 \mathrm{~min}$ and washed with Dulbecco's phosphate-buffered saline (PBS) containing $0.5 \%$ bovine serum albumin (Sigma). Cells were filtered through a 70-mm nylon membrane, and cells were counted using a hemocytometer. $1 \times 10^{6}$ cells were incubated with either fluorescein isothiocyanate (FITC)- or phycoerythrin (PE)conjugated antibodies for $30 \mathrm{~min}$. The following surface CD markers were tested: CD29/PE, CD31/PE, CD34/ FITC, CD44/FITC, CD45/FITC, CD54/FITC, CD73/ FITC, CD90/FITC, CD105/PE, HLA-ABC/FITC, and HLA-DR-DP-DQ/FITC (BD Biosciences, NJ, USA). Ten thousand events were acquired for each $\mathrm{CD}$ surface marker using a Becton Dickinson FACSCalibur flow cytometer. Data were analyzed using CellQuestPro acquisition software (BD Bioscience, Franklin Lakes, NJ, USA). CD54 surface antigen-positive (CD54 $\left.{ }^{+}\right)$cells were immunoselected from the heterogeneous mix of rASCs using immunomagnetic beads from a MACS ${ }^{\circledR}$ microbead kit (Miltenyi Biotech) according to the manufacturer's protocol. $\mathrm{CD}^{+} 4^{+}$and $\mathrm{CD} 54^{-}$rASCs were centrifuged, resuspended in growth medium, and seeded in cell culture flasks for continued expansion.

\section{HIF-1 $\alpha$-transfected rASCs}

$H I F-1 \alpha$ was introduced into a pAdEasy-1 adenoviral vector system. The virus was packaged, and titer was assessed. P5 CD54 ${ }^{+}$and CD54- rASCs were infected with the HIF-1 $\alpha$-encoding adenovirus at $90 \%$ confluence, as determined by fluorescence microscopy. Prior to infection, cells were washed with infection buffer three times and incubated at RT for $10 \mathrm{~min}$. Infection was carried out with a multiplicity of infection of $50 \mathrm{pfu} /$ cell in $1 \mathrm{ml}$ of infection buffer at RT for $60 \mathrm{~min}$. After infection, rASCs were incubated at $37^{\circ} \mathrm{C}$ with $5 \% \mathrm{CO}_{2}$ in a humidified atmosphere. Three d later, rASCs were subcultured for use in the following experiments.

\section{Influence of HIF-1 $\alpha$ on rASCs proliferation in vitro}

For cell proliferation assays, HIF-1 $\alpha$-transfected rASCs, blank-transfected rASCs, and control rASCs were cultured in 96-well plates at $2 \times 10^{4}$ cells/well with culture medium for up to $9 \mathrm{~d}$. rASCs proliferation was measured using Cell Counting Kit 8 (CCK-8, Kumamoto, Japan) assay and a microplate reader (ELx800, BioTek) at $450 \mathrm{~nm}$, as described previously [6].
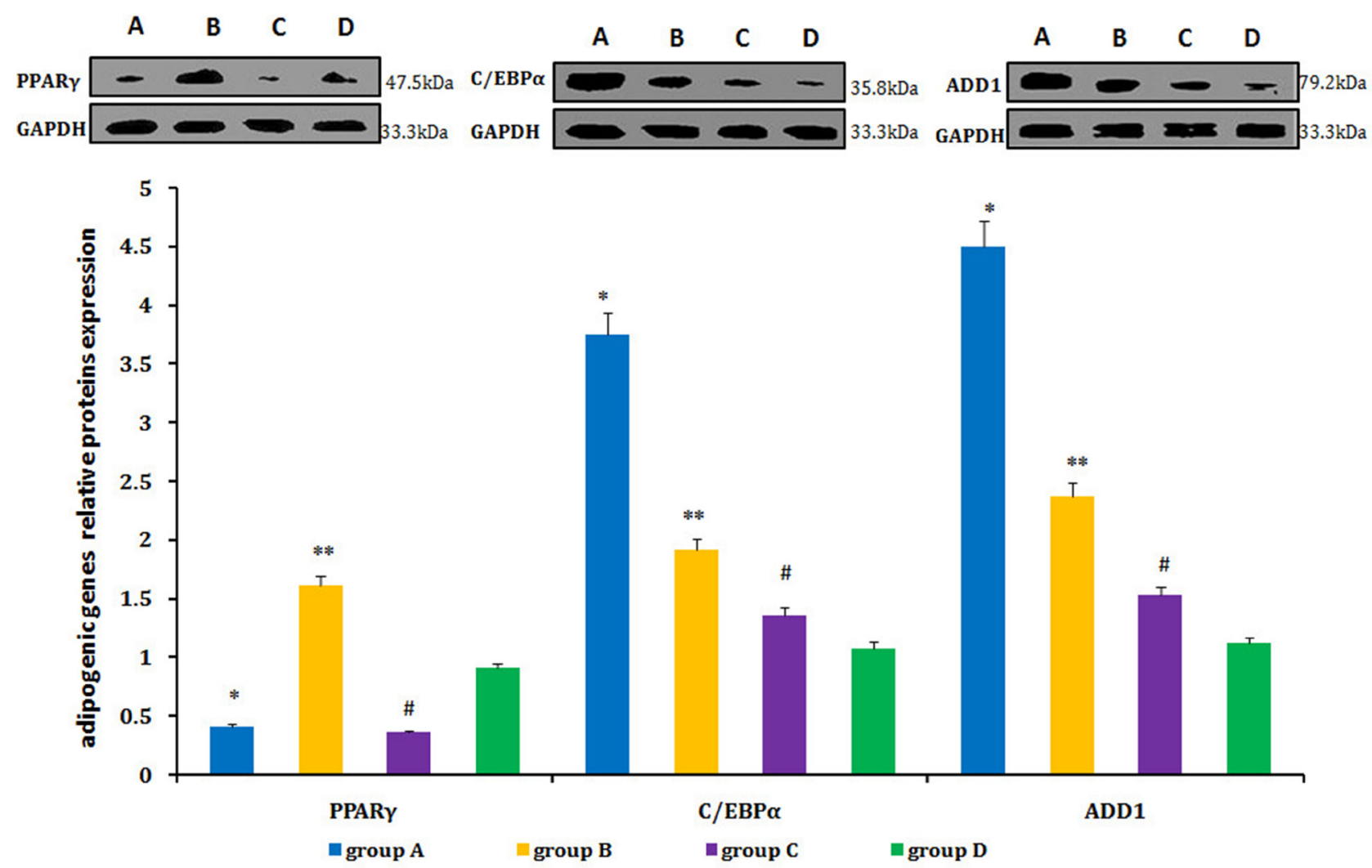

Figure 12: C/EBP $\alpha$ and ADD1 protein levels were higher in the neogenetic fat flaps of group $A$ than in the other three groups. PPAR $\gamma$ was downregulated in neogenetic fat flaps of groups $\mathrm{A}$ and $\mathrm{C}$ compared with the other two groups. $* P<0.01, * * P<0.01$, ${ }^{\#} P<0.01$. 


\section{Paracrine function of rASCs after transfected HIF-1 $\alpha$ in vitro}

After 3 and $7 \mathrm{~d}$, untransfected and transfected rASCs culture supernatants were collected for analysis by ELISA. HGF, VEGF, b-FGF, ET-1, IGF-2 and HSP70 levels were measured using Quantikine colorimetric sandwich ELISA kits (R\&D Systems, Minneapolis, MN, USA) according to the manufacturer's instructions.

\section{Influence of HIF-1 $1 \alpha$ on rASCs adipogenic differentiation in vitro}

For adipogenesis assays, HIF- $1 \alpha$-transfected CD54 ${ }^{+}$rASCs (group A), CD54 ${ }^{+}$rASCs (group B), HIF$1 \alpha$-transfected CD54rASCs (group C), and CD54rASCs(group D) were cultured in 6-well plates with adipogenic induction medium containing $200 \mu \mathrm{M}$ indomethacin, $10 \mu \mathrm{M}$ insulin, $0.5 \mathrm{mM}$ 3-isobutyl-1methylxanthine, and $1 \mu \mathrm{M}$ dexamethasone at a seeding density of 500 cells $/ \mathrm{mm}^{2}$ for up to $14 \mathrm{~d}$. Adipogenic differentiation was determined by oil red $\mathrm{O}$ staining. Briefly, cultured cells were air dried for $30 \mathrm{~min}$, and then fixed in 10\% formalin for $5 \mathrm{~min}$. Cells were rinsed three times with distilled water, and immersed in absolute propylene glycol for $5 \mathrm{~min}$ to avoid transferring water into the oil red O. Cells were stained in oil red O solution for 8 $\min$ at $60^{\circ} \mathrm{C}$ in an oven, rinsed with $85 \%$ propylene glycol for $5 \mathrm{~min}$,. rinsed with distilled water, and then stained in Gill's hematoxylin solution for $30 \mathrm{sec}$. Cells were thoroughly washed with running water for $3 \mathrm{~min}$, rinsed twice with distilled water, and mounted with glycerin jelly or aqueous mounting medium. Upon observation of the samples, lipids appeared red and nuclei appeared pale blue. Adipocyte density for each sample was measured in 10 visual fields under the same magnification in a double-blind manner. Cell numbers were normalized to square millimeters. Lipids were extracted from cells with $100 \%$ isopropanol and gentle shaking for $5 \mathrm{~min}$. Lipid concentrations were measured based on absorbance at 510 $\mathrm{nm}$ in triplicate for each sample.

\section{rASCS-loaded scaffold implantation in vivo}

All animal procedures were performed in accordance with the guidelines of the Guangxi Medical University Animal Care and Use Committee. Twenty New Zealand rabbits (aged 3-4 months old, weighing

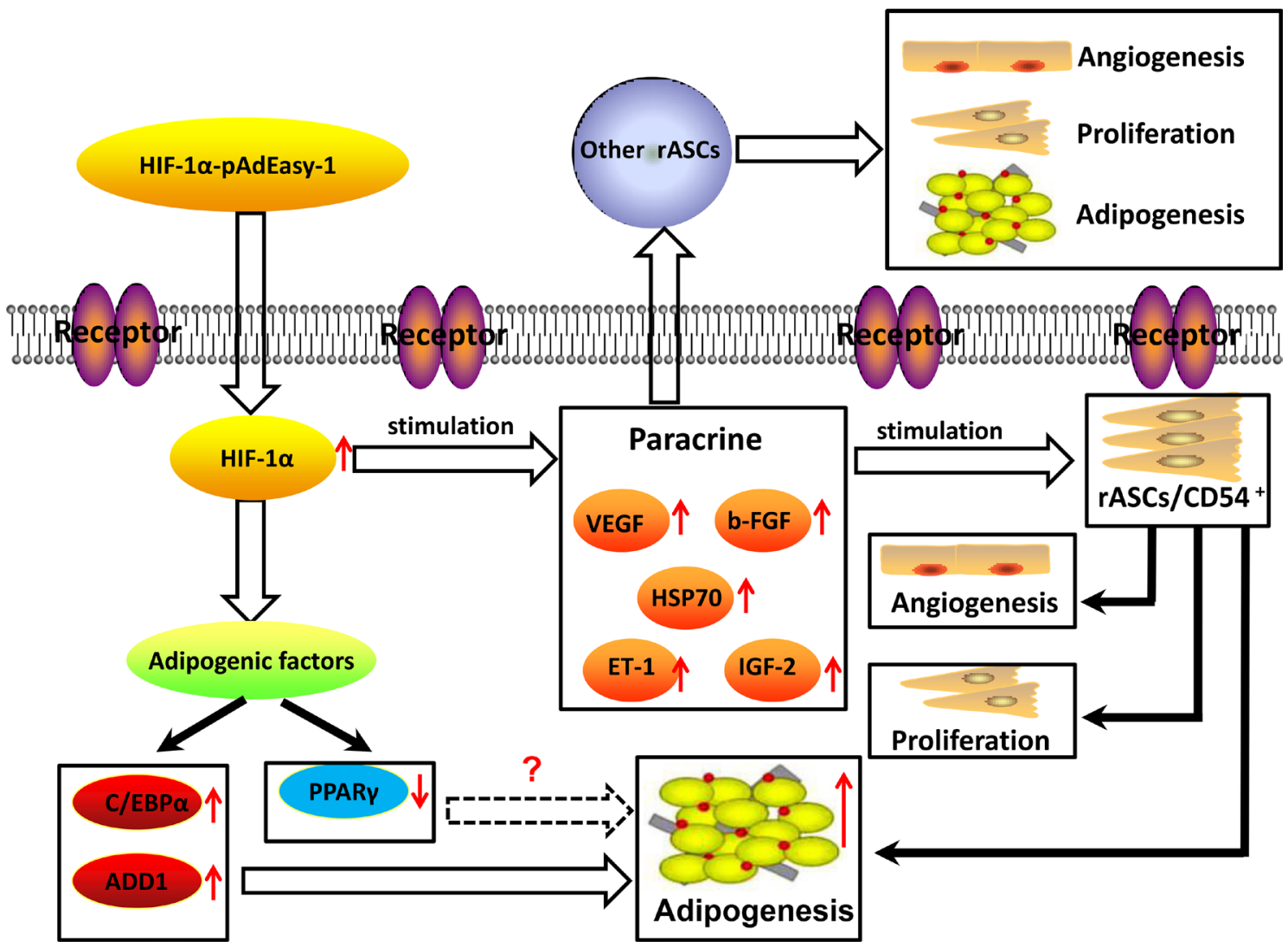

Figure 13: Graphical model of signaling in rASCs adipogenic differentiation. $\mathrm{CD}^{+} 4^{+} \mathrm{rASC}$ exhibit stronger adipogenic differentiation potential in vitro and in vivo. HIF-1 $\alpha$ transfection augmented this effect, and upregulated cell proliferation and paracrine function. rASCs adipogenic differentiation could thus be prompted by HIF- $1 \alpha$ in a C/EBP $\alpha$-dependent, rather than PPAR $\gamma$-dependent pathway. 
Table 3: Primer sequences

\begin{tabular}{lll}
\hline Gene name (rabbit) & \multicolumn{1}{c}{ Forward $\left(\mathbf{5}^{\prime}\right.$ to $\mathbf{3}^{\prime}$ ) } & \multicolumn{1}{c}{ Reverse $\mathbf{( 5}^{\prime}$ to $\mathbf{3}^{\prime}$ ) } \\
\hline HIF-1 $\alpha$ & TGAAACTCAAGCAACGGTCA & GGCTCCTTCTTCAGTTTGTCA \\
VEGF & CTCTACCTCCACCATGCCAA & CTCCAGGCTTTCATCATTGCAG \\
b-FGF & TTCACAGCCCTGACCGAGA & CTGTCCCTTGTGCCGTCCA \\
ET-1 & CCAAGCAGGAACGGAACTCA & CACTTTCTGCTCTCGGTGGA \\
IGF-2 & CATTGTGGAGGAATGCTGCTTC & CCCGGTGTCAAGCTGAAATAAC \\
HSP70 & AACAACCTGCTGGGGCGCTT & CCTTGCCCGTGCTCTTGTCGGT \\
PPAR $\gamma$ & AATCAAAGTGGAACCTGCATC & TTCGGAAGAAACCCTTGCAT \\
C/EBP $\alpha$ & AGCCGATATCTTGTATCTAGCCT & CTCATTTTGGCAAGTATCTGAGC \\
ADD1 1 & TATGACCGCAAACGTCCCG & ATGAGCTGAGACCACCCG \\
GAPDH & AATCCACTGGCGTCTTCACC & GCCCCTCCACAATGCCGA \\
\hline
\end{tabular}

$2.0 \pm 0.3 \mathrm{~kg}$ ) were used to establish an autologous cell implantation model. $\mathrm{CD} 54^{+}$and $\mathrm{CD} 54^{-}$rASCs were cultured with adipogenic induction media for one week before implantation. Collagen scaffolds loaded with cell suspensions were essentially gel masses containing $1.0 \mathrm{ml}$ of $1 \times 10^{7} / \mathrm{ml} \mathrm{HIF-1} \alpha$-transfected CD54 ${ }^{+} \mathrm{rASCs}$ (group A), $1.0 \mathrm{ml}$ of $1 \times 10^{7} / \mathrm{ml} \mathrm{CD} 54^{+} \mathrm{rASCs}$ (group B), $1.0 \mathrm{ml}$ of $1 \times 10^{7} / \mathrm{ml} \mathrm{HIF-1} \alpha$-transfected CD54rASCs (group C), or $1.0 \mathrm{ml}$ of $1 \times 10^{7} / \mathrm{ml} \mathrm{CD54rASCs} \mathrm{(group} \mathrm{D).} \mathrm{All}$ compounds were implanted into the muscular fasciae on the backs of rabbits. Each implantation site randomly received one of these four scaffolds.

\section{Neogenetic fat flap wet weight measurement and histopathological examination}

At 12 weeks post-implantation, all transplants (i.e., neogenetic fat flaps) were excised from the muscular fasciae and weighed using a standard electronic balance. Transplants were then fixed in formalin and embedded in paraffin. Tissue sections from the center of the dissected regenerative tissue biopsy were stained with hematoxylin and eosin (H\&E) using standard procedures and examined by light microscopy. MVD was assessed by counting microvessels in 10 fields of each H\&E-stained slide (40× magnification; performed by two blinded reviewers).

\section{Oil red $O$ staining and quantitative measurement of adipogenesis in vivo}

Neogenetic fat flap tissues samples were embedded in paraffin, cut into 5- $\mu \mathrm{m}$-thick slices, and observed by fluorescence microscopy. Cyrosections were stained with oil red $\mathrm{O}$ and washed twice with PBS. Adipocyte densities were measured in a double-blind manner in 10 visual fields under the same magnification. Cell numbers were normalized to square millimeters. Lipids were extracted from cells with $100 \%$ isopropanol and gentle shaking for $5 \mathrm{~min}$. Lipid concentrations were measured based on absorbance at $510 \mathrm{~nm}$ in triplicate for each sample.

\section{Real-time quantitative PCR (qPCR)}

Total RNA was extracted from each group using TRIzol according to the manufacturer's protocol (Invitrogen, USA). First-strand cDNA was synthesized from $1 \mu \mathrm{g}$ of RNA with viral reverse transcriptase (TaKaRa, Japan) and used for real-time qPCR. HIF-1 $\alpha$, VEGF, b-FGF, ET-1, IGF-2, HSP70, PPAR $\gamma, \mathrm{C} / \mathrm{EBP} \alpha$, and ADD1 levels were quantified using an ABI 7300 real-time PCR system (Applied Biosystems, USA) with SYBR green PCR reaction mix (TaKaRa, Japan). Primers are listed in Table 3. The following program was used: $95^{\circ} \mathrm{C}$ for $5 \mathrm{~min}, 40$ cycles of $95^{\circ} \mathrm{C}$ for $15 \mathrm{sec}$, annealing for $1 \mathrm{~min}$, and $72^{\circ} \mathrm{C}$ for $30 \mathrm{sec}$. A melting analysis and agarose gel electrophoresis were performed to confirm PCR product specificities. Relative gene expression was analyzed using the $2^{-\Delta \Delta \mathrm{Ct}}$ method, normalized to GAPDH expression, and data are presented as fold change relative to the control.

\section{Protein extraction and western blotting}

Neogenetic fat flap samples from each group were harvested for western blot analysis, and whole cell extracts were obtained. Cell pellets were sonicated in extraction buffer, and extracts were quantified using a Bio-Rad DC protein assay kit (Bio-Rad, Hercules, California, USA). Equal amounts of protein were resolved by 4-12\% SDSPAGE and transferred to PVDF membranes (Millipore, Bedford, Massachusetts, USA). Membranes were blocked with blocking solution (Pierce, Rockford, Illinois, USA). The following primary antibodies (all anti-rabbit) were used: HIF-1 $\alpha$, VEGF, b-FGF, ET-1, IGF-2, HSP70, PPAR $\gamma$, $\mathrm{C} / \mathrm{EBP} \alpha$, and ADD1 (all from Abcam, London, UK). Horseradish peroxidase-conjugated secondary antibodies and enhanced chemiluminescence substrates (Supersignal 
West Dura Detection System; Pierce) were used for primary antibody detection.

\section{Statistical analysis}

Data are shown as means \pm standard deviations (SD). We used analysis of variance (ANOVA) to compare group means. This approach accounts for intra- and intergroup variation. When ANOVA of the four means revealed statistically significant differences, the means of any two groups were compared using paired $t$-tests. $P<0.05$ (twotailed) was considered statistically significant. All data were analyzed using SPSS for Windows version 17.0 (Chicago, Illinois, USA).

\section{CONFLICTS OF INTEREST}

The authors disclose no conflicts of interest.

\section{GRANT SUPPORT}

This work was supported by the National Nature Science Foundation of China (81560316), the Scientific Research \& Technology Development Program of Guangxi (Guikegong1598012-1), the Guangxi Natural Science Foundation (2016GXNSFDA380016), and the Scientific Research \& Technology Development Program of Nanning City (20153089, zc20153002).

\section{REFERENCES}

1. Pati F, Ha DH, Jang J, Han HH, Rhie JW, Cho DW. Biomimetic 3D tissue printing for soft tissue regeneration. Biomaterials. 2015; 62:164-75.

2. Bellas E, Lo TJ, Fournier EP, Brown JE, Abbott RD, Gil ES, Marra KG, Rubin JP, Leisk GG, Kaplan DL. Injectable silk foams for soft tissue regeneration. Adv Healthc Mater. $2015 ; 4: 452-9$.

3. Jaikumar D, Sajesh KM, Soumya S, Nimal TR, Chennazhi KP, Nair SV, Jayakumar R. Injectable alginateO-carboxymethyl chitosan/nano fibrin composite hydrogels for adipose tissue engineering. Int J Biol Macromol. 2015; 74:318-26.

4. Philips BJ, Marra KG, Rubin JP. Adipose stem cell-based soft tissue regeneration. Expert Opin Biol Ther. 2012; 12:155-63.

5. Lequeux $\mathrm{C}$, Oni $\mathrm{G}$, Wong $\mathrm{C}$, Damour $\mathrm{O}$, Rohrich $\mathrm{R}$, Mojallal A, Brown SA. Subcutaneous fat tissue engineering using autologous adipose-derived stem cells seeded onto a collagen scaffold. Plast Reconstr Surg. 2012; 130:1208-17.

6. Li H, Han Z, Liu D, Zhao P, Liang S, Xu K. Autologous platelet-rich plasma promotes neurogenic differentiation of human adipose-derived stem cells in vitro. Int J Neurosci. 2013; 123:184-90.
7. Volz AC, Huber B, Kluger PJ. Adipose-derived stem cell differentiation as a basic tool for vascularized adipose tissue engineering. Differentiation. 2016; 92:52-64.

8. Kelly BD, Hackett SF, Hirota K, Oshima Y, Cai Z, BergDixon S, Rowan A, Yan Z, Campochiaro PA, Semenza GL. Cell type-specific regulation of angiogenic growth factor gene expression and induction of angiogenesis in nonischemic tissue by a constitutively active form of hypoxia-inducible factor 1 . Circ Res. 2003; 93:1074-81.

9. Declercq HA, De Caluwé T, Krysko O, Bachert C, Cornelissen MJ. Bone grafts engineered from human adipose-derived stem cells in dynamic 3D-environments. Biomaterials. 2013; 34:1004-17.

10. Estes BT, Diekman BO, Gimble JM, Guilak F. Isolation of adipose-derived stem cells and their induction to a chondrogenic phenotype. Nat Protoc. 2010; 5:1294-311.

11. Mizuno H, Itoi Y, Kawahara S, Ogawa R, Akaishi S, Hyakusoku H. In vivo adipose tissue regeneration by adipose-derived stromal cells isolated from GFP transgenic mice. Cells Tissues Organs. 2008; 187:177-85.

12. Makarevich PI, Boldyreva MA, Gluhanyuk EV, Efimenko AY, Dergilev KV, Shevchenko EK, Sharonov GV, Gallinger JO, Rodina PA, Sarkisyan SS, Hu YC, Parfyonova YV. Enhanced angiogenesis in ischemic skeletal muscle after transplantation of cell sheets from baculovirustransduced adipose-derived stromal cells expressing VEGF165. Stem Cell Res Ther. 2015; 6:204.

13. Sowa $Y$, Kishida $T$, Imura $T$, Numajiri $T$, Nishino $K$, Tabata Y, Mazda O. Adipose-Derived Stem Cells Promote Peripheral Nerve Regeneration In Vivo without Differentiation into Schwann-Like Lineage. Plast Reconstr Surg. 2016; 137:318e-330e.

14. Fu N, Yang X, Ba K, Fu Y, Wei X, Yue Y, Li G, Yao Y, Chen J, Cai X, Liang C, Ge Y, Lin Y. Low-intensity pulsed ultrasound induced enhanced adipogenesis of adiposederived stem cells. Cell Prolif. 2013; 46:312-9.

15. Clevenger TN, Hinman CR, Ashley Rubin RK, Smither K, Burke DJ, Hawker CJ, Messina D, Van Epps D, Clegg DO. Vitronectin-Based, Biomimetic Encapsulating Hydrogel Scaffolds Support Adipogenesis of Adipose Stem Cells. Tissue Eng Part A. 2016; 22:597-609.

16. Brännmark C, Paul A, Ribeiro D, Magnusson B, Brolén G, Enejder A, Forslöw A. Increased adipogenesis of human adipose-derived stem cells on polycaprolactone fiber matrices. PLoS One. 2014; 9:e113620.

17. Young DA, Choi YS, Engler AJ, Christman KL. Stimulation of adipogenesis of adult adipose-derived stem cells using substrates that mimic the stiffness of adipose tissue. Biomaterials. 2013; 34:8581-8.

18. Im W, Chung JY, Kim SH, Kim M. Efficacy of autologous serum in human adipose-derived stem cells; cell markers, growth factors and differentiation. Cell Mol Biol (Noisy-legrand). 2011; 57:OL1470-5. 
19. Cervelli V, Scioli MG, Gentile P, Doldo E, Bonanno E, Spagnoli LG, Orlandi A. Platelet-rich plasma greatly potentiates insulin-induced adipogenic differentiation of human adipose-derived stem cells through a serine/threonine kinase Akt-dependent mechanism and promotes clinical fat graft maintenance. Stem Cells Transl Med. 2012; 1:206-20.

20. Xu FT, Li HM, Yin QS, Liu DL, Nan H, Zhao PR, Liang SW. Human breast adipose-derived stem cells transfected with the stromal cell-derived factor-1 receptor CXCR4 exhibit enhanced viability in human autologous free fat grafts. Cell Physiol Biochem. 2014; 34:2091-104.

21. Xu FT, Liang ZJ, Li HM, Peng QL, Huang MH, Li de Q, Liang YD, Chi GY, Li de H, Yu BC, Huang JR. Ginsenoside Rg1 and platelet-rich fibrin enhance human breast adipose-derived stem cell function for soft tissue regeneration. Oncotarget. 2016; 7:35390-403. doi: 10.18632/oncotarget.9360.

22. de Runz A, Brix M, Gisquet H, Pujo J, Minetti C, Colson T, Sorin T, Agrinier N, Simon E. Satisfaction and complications after lower body lift with autologous gluteal augmentation by island fat flap: 55 case series over 3 years. J Plast Reconstr Aesthet Surg. 2015; 68:410-8.

23. Inchingolo F, Tatullo $M$, Pacifici A, Gargari M, Inchingolo AD, Inchingolo AM, Dipalma G, Marrelli M, Abenavoli FM, Pacifici L.Use of dermal-fat grafts in the post-oncological reconstructive surgery of atrophies in the zygomatic region: clinical evaluations in the patients undergone to previous radiation therapy. Head Face Med. 2012; 8:33.

24. Podmelle F, Metelmann HR, Waite P. Endoscopic abdominoplasty providing a perforator fat flap for treatment of hemi-facial microsomia. J Craniomaxillofac Surg. 2012; 40:665-7.

25. Yamashita K, Discher DJ, Hu J, Bishopric NH, Webster KA. Molecular regulation of the endothelin-1 gene by hypoxia. Contributions of hypoxia-inducible factor-1, activator protein-1, GATA-2, AND p300/CBP. J Biol Chem. 2001; 276:12645-53.

26. Rey S, Semenza GL. Hypoxia-inducible factor-1-dependent mechanisms of vascularization and vascular remodelling. Cardiovasc Res. 2010; 86:236-42.

27. Feng N, Chen H, Fu S, Bian Z, Lin X, Yang L, Gao Y, Fang J, Ge Z. HIF- $1 \alpha$ and HIF- $2 \alpha$ induced angiogenesis in gastrointestinal vascular malformation and reversed by thalidomide. Sci Rep. 2016; 6:27280.

28. Kütscher C, Lampert FM, Kunze M, Markfeld-Erol F, Stark GB, Finkenzeller G. Overexpression of hypoxiainducible factor-1 alpha improves vasculogenesis-related functions of endothelial progenitor cells. Microvasc Res. 2016; 105:85-92.

29. Hu K, Babapoor-Farrokhran S, Rodrigues M, Deshpande M, Puchner B, Kashiwabuchi F, Hassan SJ, Asnaghi L, Handa JT, Merbs S, Eberhart CG, Semenza GL, Montaner S, Akrit Sodhi. Hypoxia-inducible factor 1 upregulation of both VEGF and ANGPTL4 is required to promote the angiogenic phenotype in uveal melanoma. Oncotarget. 2016; 7:7816-28. doi: 10.18632/oncotarget.6868.
30. Barteczek P, Li L, Ernst AS, Böhler LI, Marti HH, Kunze R. Neuronal HIF- $1 \alpha$ and HIF-2 $\alpha$ deficiency improves neuronal survival and sensorimotor function in the early acute phase after ischemic stroke. J Cereb Blood Flow Metab. 2017; 37:291-306.

31. Gao W, Qiao X, Ma S, Cui L. Adipose-derived stem cells accelerate neovascularization in ischaemic diabetic skin flap via expression of hypoxia-inducible factor- $1 \alpha$. J Cell Mol Med. 2011; 15:2575-85.

32. Kakudo N, Morimoto N, Ogawa T, Taketani S, Kusumoto K. Hypoxia Enhances Proliferation of Human Adipose-Derived Stem Cells via HIF-1 $\alpha$ Activation. PLoS One. 2015; 10:e0139890.

33. Wang WW, Li ZZ, Wang W, Jiang Y, Cheng J, Lu S, Zhang JY. Enhanced renoprotective effect of HIF-1 $\alpha$ modified human adipose-derived stem cells on cisplatininduced acute kidney injury in vivo. Sci Rep. 2015; 5:10851.

34. Bigot N, Guérillon C, Loisel S, Bertheuil N, Sensebé L, Tarte K, Pedeux R. ING1b negatively regulates HIF1 $\alpha$ protein levels in adipose-derived stromal cells by a SUMOylation-dependent mechanism. Cell Death Dis. 2015; 6:e1612.

35. Yue Y, Zhang P, Liu D, Yang JF, Nie C, Yang D. Hypoxia preconditioning enhances the viability of ADSCs to increase the survival rate of ischemic skin flaps in rats. Aesthetic Plast Surg. 2013; 37:159-70.

36. Hemmingsen M, Vedel S, Skafte-Pedersen P, Sabourin D, Collas P, Bruus H, Dufva M. The role of paracrine and autocrine signaling in the early phase of adipogenic differentiation of adipose-derived stem cells. PLoS One. 2013; 8:e63638.

37. Xu M, Palmer AK, Ding H, Weivoda MM, Pirtskhalava T, White TA, Sepe A, Johnson KO, Stout MB, Giorgadze N, Jensen MD, LeBrasseur NK, Tchkonia T, et al. Targeting senescent cells enhances adipogenesis and metabolic function in old age. Elife. 2015; 4:e12997.

38. Scioli MG, Bielli A, Gentile P, Mazzaglia D, Cervelli V, Orlandi A. The biomolecular basis of adipogenic differentiation of adipose-derived stem cells. Int J Mol Sci. 2014; 15:6517-26.

39. Mitchell A, Ashton L, Yang XB, Goodacre R, Smith A, Kirkham J. Detection of early stage changes associated with adipogenesis using Raman spectroscopy under aseptic conditions. Cytometry A. 2015; 87:1012-9.

40. Jiang C, Sun J, Dai Y, Cao P, Zhang L, Peng S, Zhou Y, Li G, Tang J, Xiang J. HIF-1A and C/EBPs transcriptionally regulate adipogenic differentiation of bone marrow-derived MSCs in hypoxia. Stem Cell Res Ther. 2015; 6:21.

41. Konno M, Hamazaki TS, Fukuda S, Tokuhara M, Uchiyama H, Okazawa H, Okochi H, Asashima M. Efficiently differentiating vascular endothelial cells from adipose tissue-derived mesenchymal stem cells in serum-free culture. Biochem Biophys Res Commun. 2010; 400:461-5. 
41. Volz AC, Huber B, Schwandt AM, Kluger PJ. EGF and hydrocortisone as critical factors for the co-culture of adipogenic differentiated ASCs and endothelial cells. Differentiation. 2017; 95:21-30.

42. Procházka V, Jurčíková J, Laššák O, Vítková K, Pavliska L, Porubová L, Buszman PP, Krauze A, Fernandez C, Jalůvka F, Špačková I, Lochman I, Jana D, et al. Therapeutic Potential of Adipose-Derived Therapeutic Factor Concentrate for Treating Critical Limb Ischemia. Cell Transplant. 2016; 25:1623-1633.

43. Horikoshi-Ishihara H, Tobita M, Tajima S, Tanaka R, Oshita T, Tabata Y, Mizuno H. Coadministration of adiposederived stem cells and control-released basic fibroblast growth factor facilitates angiogenesis in a murine ischemic hind limb model. J Vasc Surg. 2016; 64:1825-1834.e1.
44. Chen L, Xu Y, Zhao J, Zhang Z, Yang R, Xie J, Liu X, Qi S. Conditioned medium from hypoxic bone marrow-derived mesenchymal stem cells enhances wound healing in mice. PLoS One. 2014; 9:e96161.

45. Xu FT, Li HM, Yin QS, Liang ZJ, Huang MH, Chi GY, Huang L, Liu DL, Nan H. Effect of activated autologous platelet-rich plasma on proliferation and osteogenic differentiation of human adipose-derived stem cells in vitro. Am J Transl Res. 2015; 7:257-70.

46. Cui SE, Li HM, Liu DL, Nan H, Xu KM, Zhao PR, Liang SW. Human breast adipose-derived stem cells: characterization and differentiation into mammary glandlike epithelial cells promoted by autologous activated platelet-rich plasma. Mol Med Rep. 2014; 10:605-14. 